\title{
MONITORING LAND USE/LAND COVER CHANGES IN A RIVER BASIN DUE TO URBANIZATION USING REMOTE SENSING AND GIS APPROACH
}

\author{
Satyavati Shukla $^{\text {a, } *, \text { M. V. Khire }}{ }^{\text {a }}$, S. S. Gedam ${ }^{\text {a }}$ \\ ${ }^{a}$ Centre of Studies in Resources Engineering, Indian Institute of Technology Bombay, Mumbai, India - (satyashukla, mvk, \\ shirish)@iitb.ac.in
}

Commission VI, WG VI/4

KEY WORDS: Change Detection, GIS, Land Use/Land Cover, Remote Sensing, River Basin, Urbanization

\begin{abstract}
:
Faster pace of urbanization, industrialization, unplanned infrastructure developments and extensive agriculture result in the rapid changes in the Land Use/Land Cover (LU/LC) of the sub-tropical river basins. Study of LU/LC transformations in a river basin is crucial for vulnerability assessment and proper management of the natural resources of a river basin. Remote sensing technology is very promising in mapping the LU/LC distribution of a large region on different spatio-temporal scales. The present study is intended to understand the LU/LC changes in the Upper Bhima river basin due to urbanization using modern geospatial techniques such as remote sensing and GIS. In this study, the Upper Bhima river basin is divided into three adjacent sub-basins: Mula-Mutha sub-basin (ubanized), Bhima sub-basin (semi-urbanized) and Ghod sub-basin (unurbanized). Time series LU/LC maps were prepared for the study area for a period of 1980, 2002 and 2009 using satellite datasets viz. Landsat MSS (October, 1980), Landsat ETM+ (October, 2002) and IRS LISS III (October 2008 and November 2009). All the satellite images were classified into five LU/LC classes viz. built-up lands, agricultural lands, waterbodies, forests and wastelands using supervised classification approach. Post classification change detection method was used to understand the LU/LC changes in the study area. Results reveal that built up lands, waterbodies and agricultural lands are increasing in all the three sub-basins of the study area at the cost of decreasing forests and wastelands. But the change is more drastic in urbanized Mula-Mutha sub-basin compared to the other two sub-basins.
\end{abstract}

\section{INTRODUCTION}

Sub-tropical river basins have a complex but self-sustaining ecosystem. But increasing population and their demands in these river basins are responsible for the over exploitation of the natural resources like water. Therefore, they are stressed in terms of water resources (Shukla et al., 2013). There are drastic changes in the LU/LC of these river basins due to rapidly increasing urbanization and other related anthropogenic activities. Urbanization is a phenomenon of uncontrolled growth of population in a region coupled with unplanned infrastructure developmental activities. Preparation of LULC map is necessary to understand the LULC dynamics of a region over a period of time. LU/LC map is an important input to the hydrological models. Better LU/LC map provides better results for hydrologic simulations. Hence, the study of LU/LC transformations in a river basin is crucial for vulnerability assessment, sustainable development and proper management of the river basins (Ali and Tesgaya, 2010). Remote sensing and GIS techniques are very promising in mapping the land use land cover distribution of a river basin on different spatiotemporal scales (Joshi and Gairola, 2004). They provide better LU/LC maps. But, identification of land use land cover classes by remote sensing is challenging, especially for heterogeneous land surfaces. A wide range of satellite datasets are being used to study effect of LU/LC changes such as Landsat MSS/TM (Multispectral Scanner/Thematic Mapper), ETM+ (Enhanced Thematic Mapper) and IRS LISS-III (Indian Remote Sensing Satellite) data and AVHRR (Advanced Very High Resolution Radiometer), etc. (Mohan et al., 2011).
Pixel-based image analysis (PBIA) method is used for image classification in the present study. There are two basic approaches for LU/LC classification using PBIA method viz. supervised classification and unsupervised classification. In unsupervised classification, number of classes required is provided to the software and it classifies the image into the classes based on algorithms. In supervised classification method training samples are specified based on ground truth data available. For change detection, supervised classification with maximum likelihood classifier (MLC) can reduce spectral confusion problem between some land use classes (Adepoju et al., 2006). One disadvantage of these classifications is the presence of mixed pixels. Methods used for LU/LC change detection studies can be divided into two broad categories: (a) pre-classification method for change detection and (b) postclassification method for change detection. Pre-classification method for change detection is a change detection method where value in one image pixel is subtracted from the value found in the same location in the second image. Though it is simple and quick but direct differencing does not produce any useful results. Pre-classification change detection techniques generally generate "change" vs. "no-change" maps, but do not specify the type of change. Pre-classification change detection methods include image differencing, image regression, image ratioing, vegetation index differencing, principal components analysis, etc. (Zhou et al., 2008). Post-classification change detection method involves the change analysis after independently classifying the two images of different dates. The objective of image classification is to create cluster classes from multispectral satellite imagery. This is the most

\footnotetext{
* Corresponding author.
} 
straightforward method of change detection. It involves the overlay of two or more classified images. Change areas are simply those areas which are not classified the same at different times. This method not only locates the changes, but also provides "from-to" change information. It minimizes the problems caused by variation in sensors and atmospheric conditions (Adepoju et al., 2006). In the present study, the main objective is to understand the LU/LC changes in the Upper Bhima river basin due to urbanization using modern geospatial techniques such as remote sensing and GIS.

\section{STUDY AREA}

Rapidly urbanizing Upper Bhima river basin of Maharashtra state, India is selected as the study area (Figure 1). Total area under Upper Bhima river basin is $11,259.60 \mathrm{~km}^{2}$. It has latitudinal extent of $18^{\circ} 17^{\prime}$ to $19^{\circ} 24^{\prime}$ and longitudinal extent of $73^{\circ} 20^{\prime}$ to $74^{\circ} 43^{\prime}$. In the present study to monitor the LU/LC changes and to understand the effects of urbanization on the Upper Bhima river basin, the entire basin is divided into three adjacent sub-basins: Mula-Mutha sub-basin (urbanized), Bhima sub-basin (semi-urbanized) and Ghod sub-basin (unurbanized). The Mula-Mutha sub-basin is a rapidly urbanizing sub-basin. It is experiencing an unprecedented population growth and urbanization in recent times. This subbasin comprises of mega city Pune and Pimpri-Chinchwad industrial complex area which are spreading continuously. Bhima sub-basin and Ghod sub-basin are relatively semiurbanized and unurbanized. The area covered in Mula-Mutha, Bhima and Ghod sub-basin are 2,918.20 km², 3,806.20 km² and $4,535.20 \mathrm{~km}^{2}$ respectively.

Upper Bhima river basin is a sub-tropical river basin which falls in a semi-arid climatic zone. Western part of the basin is having Western Ghat mountain ranges which are the biological hotspots and the eastern part of the basin is comparatively flat. Bhima, Mula-Mutha and Ghod rivers are the important tributaries of the Krishna river. The river basin receives most of the rains $(\sim 85 \%)$ from South-West monsoon (June to midOctober). The precipitation pattern in this sub-watershed is highly uneven. Rainfall intensity in western parts is much higher than eastern parts. The average annual rainfall is about $741 \mathrm{~mm}$ and the rainfall is accompanied with heavy storms causing runoff and soil erosion. April and May are the hottest months in the basin. Mean annual temperature is about $24.88^{\circ} \mathrm{C}$, with mean minimum and maximum temperatures $17.76^{\circ} \mathrm{C}$ and $31.59^{\circ} \mathrm{C}$, respectively (NIC, 2009). Geology is mainly composed of basaltic lava flows (100-300 m). Major soil group in the basin is: medium black soil. Due to faster pace of urbanization, industrialization and extensive agriculture there is rapid changes in LU/LC of this basin. This river basin is suffering from the chronic water scarcity (Gartley et al., 2009).

\section{DATA USED AND METHODOLOGY}

This study required following datasets: time series satellite data [Landsat MSS (October1980), Landsat ETM+ (October 2002) and IRS LISS III (October 2008 and November 2009)] of spatial-resolution $60 \mathrm{~m}, 30 \mathrm{~m}$ and $23.5 \mathrm{~m}$ respectively. Besides the satellite data, DEM data, Survey of India toposheets and demography datasets of Pune city were also required for the study. ERDAS Imagine image processing software and ArcGIS software packages are also used for this study.

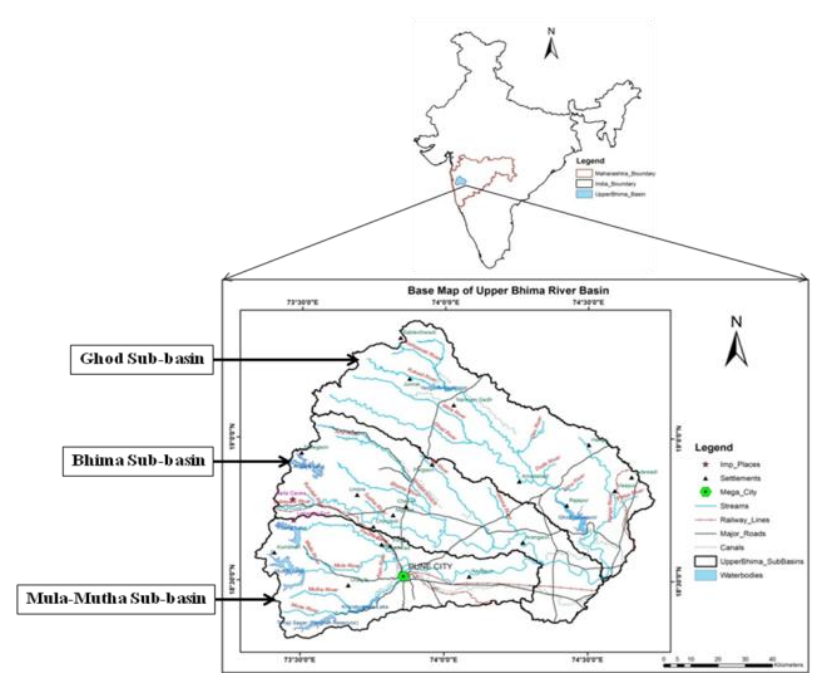

Figure 1: Location Map of Upper Bhima Basin

This study is done into two stages: first the population growth was studied for the Pune district of Maharashtra state, India from 1981 to 2011 to observe the patterns of population growth in the Pune city. In second stage, the spatio-temporal LU/LC changes were studied for the three sub-basins of the Upper Bhima river basin. For this study, the time series satellite datasets of the year 1980, 2002 and 2009 were used to prepare the LU/LC distribution maps and for their related analysis. ERDAS Imagine and ArcGIS software packages were used for image classification and analysis. The October datasets were used to reduce the seasonal effect on agricultural lands. The National Remote Sensing Centre's standard LU/LC classification system was followed for the classification. Level1 classes of the standard classification system were used for the image classification. Each satellite image was classified into five land use land cover classes using Maximum likelihood classifier (MLC) of supervised classification approach. Five major LU/LC classes identified in the study area were built-up lands, forests, agricultural lands, waterbodies and wastelands. The classification was followed by the field verification and accuracy assessment. Post classification change detection method was used to study the changes in LU/LC of Mula-Mutha sub-watershed.

\section{RESULTS AND DISCUSSION}

To study the changes in the LU/LC classes of the study area, supervised classification approach and post classification change detection method were used. Presence of mixed pixels is the problem encountered when classification is done using coarse resolution satellite datasets. The chances of misclassification are higher for the classes such as forest and agricultural land or wasteland and built-up land. An overall accuracy of $87 \%$ was achieved for the LU/LC maps of the study area. The area covered in Mula-Mutha, Bhima and Ghod subbasin are 2,918.20 $\mathrm{km}^{2}, 3,806.20 \mathrm{~km}^{2}$ and $4,535.20 \mathrm{~km}^{2}$ respectively. Census data of Pune city was anlysed and the results reveal that population has increased tremendously from 4.164 millions in 1981 to 9.426 millions in 2011. The industries have increased in the Pimpri-chinchwad area which lies north-west to the Pune city. The water demand has also increased with increasing urbanization and industralization in the study area. 
(2a)

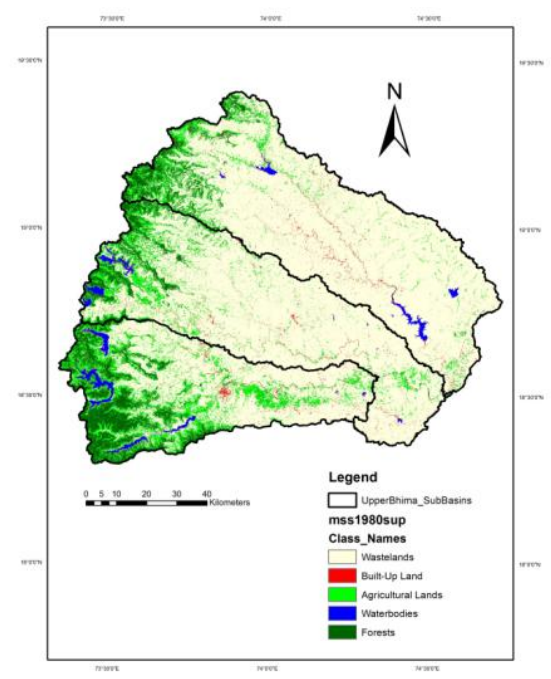

(2b)

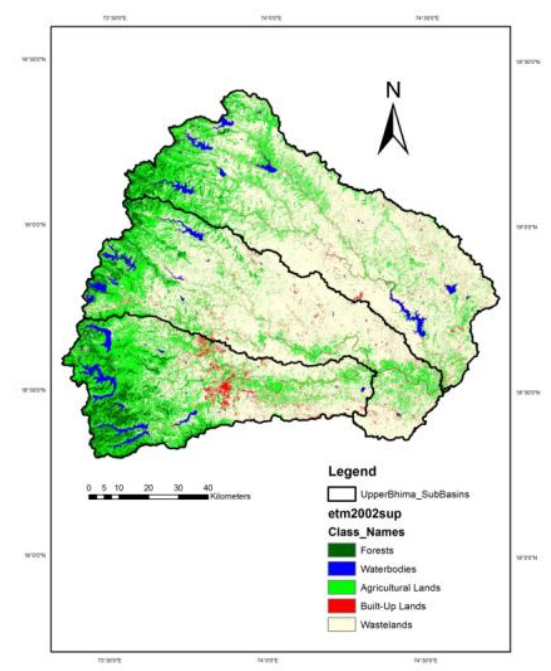

(2c)

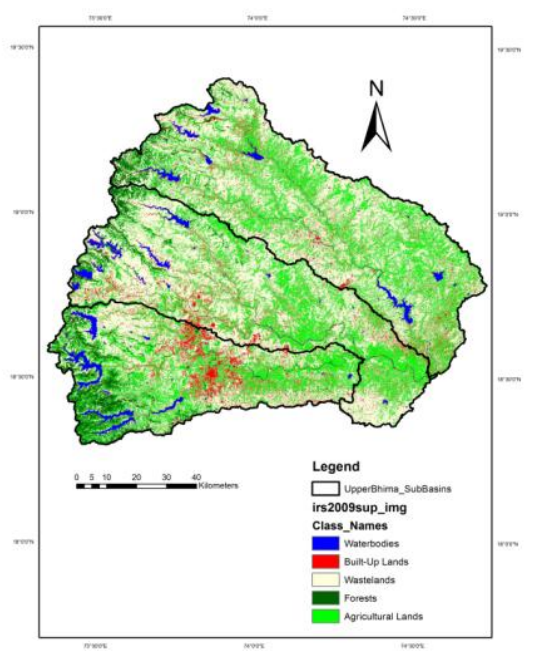

Figure 2: Spatial maps of Ghod, Bhima and Mula-Mutha subbasins of Upper Bhima river basin showing (a) LU/LC map of 1980, (b) LU/LC map of 2002, (c) LU/LC map of 2009

\subsection{LU/LC change detection in unurbanized Ghod sub- basin}

Figure 2 illustrates the LU/LC distribution maps of Ghod, Bhima and Mula-Mutha sub-basins of Upper Bhima river for the period of 1980, 2002 and 2009. From the LU/LC distribution map of unurbanized Ghod sub-basin, it was observed that this part of the basin is dominated by waste lands and agricultural lands. Some small towns and waterbodies also exist. Built up lands have increased from $0.42 \%$ in 1980 to $2.18 \%$ in 2009 due to increasing population in small towns. Also waterbodies have increased from $0.32 \%$ in 1980 to 0.73 $\%$ in 2009 to meet the water demands of increasing population for domestic and irrigation purposes. Agricultural lands are also increasing simultaneously from $2.56 \%$ in 1980 to 11.57 $\%$ in 2009 due to the increasing agricultural practices for increased food production. The increase in built up lands, waterbodies and agricultural lands are happening on the cost of forests and waste lands (Figure 3 and Table 1). Therefore, forests have decreased from $1.70 \%$ in 1980 to $1.02 \%$ in 2009 and waste lands have also decreased from $28.33 \%$ in 1980 to $17.83 \%$ in 2009 .

\begin{tabular}{lccccc}
\hline Land Use Type & \multicolumn{3}{c}{ Area (\%) } & \multicolumn{2}{c}{ Changes } \\
\cline { 2 - 6 } & $\mathbf{1 9 8 0}$ & $\mathbf{2 0 0 2}$ & $\mathbf{2 0 0 9}$ & $\begin{array}{c}\mathbf{1 9 8 0}- \\
\mathbf{2 0 0 2}\end{array}$ & $\mathbf{1 9 8 0 -}$ \\
& & & & $\mathbf{2 0 0 9}$ \\
\hline Forest Land & 1.70 & 1.05 & 1.02 & -0.65 & -0.68 \\
Agricultural Land & 2.56 & 7.22 & 11.57 & 4.66 & 9.01 \\
Built Up Land & 0.42 & 0.84 & 2.18 & 0.42 & 1.75 \\
Waterbodies & 0.32 & 0.68 & 0.73 & 0.36 & 0.41 \\
Wasteland & 28.33 & 23.54 & 17.83 & -4.78 & -10.50 \\
\hline
\end{tabular}

Table 1: LU/LC changes in unurbanized Ghod sub-basin

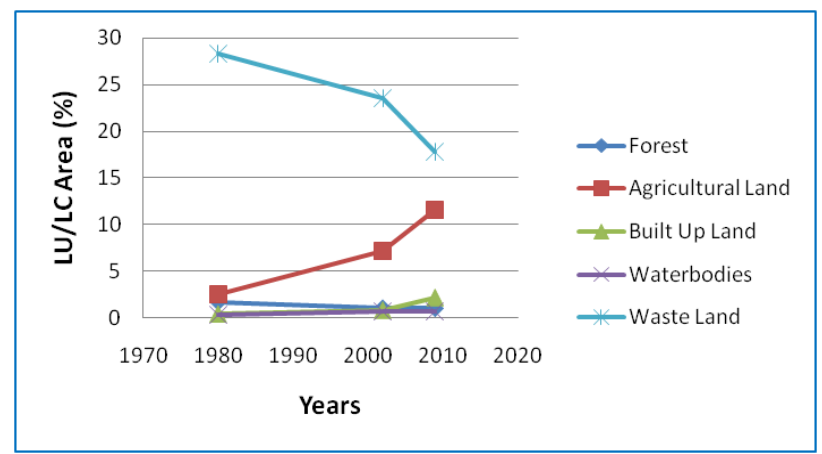

Figure 3: Chart showing LU/LC changes in unurbanized Ghod sub-basin over a period of 1980, 2002 and 2009

\subsection{LU/LC change detection in semi-urbanized Bhima sub-basin}

Semi-urbanized Bhima sub-basin is generally dominated by waste lands and agricultural lands. Some small towns and waterbodies also exist. This sub-basin is also urbanizing slowly because of the sprawl of the Pune city towards this subbasin and due to the increase in the population of the small towns. Therefore, built up lands have increased from $0.40 \%$ in 1980 to $2.50 \%$ in 2009. Waterbodies have also increased from $0.34 \%$ in 1980 to $0.78 \%$ in 2009. Again, waterbodies have increased to fulfill the domestic and agricultural water demands of the increasing population in this sub-basin. Agricultural lands are also increasing simultaneously from 3.69 $\%$ in 1980 to $10.29 \%$ in 2009 to meet the food demands of 
growing population of the sub-basin. The increase in built up lands, waterbodies and agricultural lands are happening on the cost of forests and waste lands (Figure 4). Therefore, forests have decreased from $2.02 \%$ in 1980 to $1.27 \%$ in 2009 and waste lands are also decreasing from $26.88 \%$ in 1980 to 18.50 $\%$ in 2009. Table 2 given below summarises the LU/LC changes for semi-urbanized Bhima sub-basin.

\begin{tabular}{lccccc}
\hline Land Use Type & \multicolumn{3}{c}{ Area (\%) } & \multicolumn{2}{c}{ Changes } \\
\cline { 2 - 6 } & $\mathbf{1 9 8 0}$ & $\mathbf{2 0 0 2}$ & $\mathbf{2 0 0 9}$ & $\mathbf{1 9 8 0 -}$ & $\mathbf{1 9 8 0 -}$ \\
& & & & $\mathbf{2 0 0 2}$ & $\mathbf{2 0 0 9}$ \\
\cline { 2 - 6 } & 2.02 & 1.34 & 1.27 & -0.68 & -0.75 \\
Forest Land & 3.69 & 7.23 & 10.29 & 3.54 & 6.59 \\
Agricultural Land & 0.40 & 0.99 & 2.50 & 0.60 & 2.11 \\
Built Up Land & 0.34 & 0.55 & 0.78 & 0.21 & 0.44 \\
Waterbodies & 26.88 & 23.23 & 18.50 & -3.66 & -8.38 \\
Wasteland & & & & & \\
\hline
\end{tabular}

Table 2: LU/LC changes in semi-urbanized Bhima sub-basin

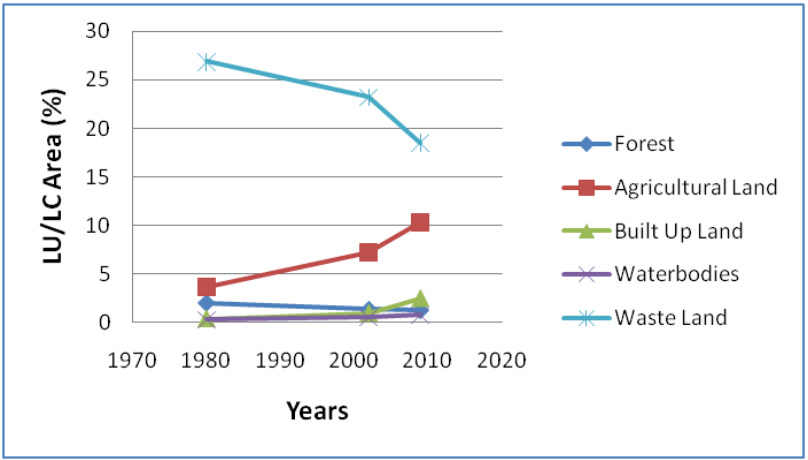

Figure 4: Chart showing LU/LC changes in semi-urbanized Bhima sub-basin over a period of 1980, 2002 and 2009

\subsection{LU/LC change detection in urbanized Mula-Mutha sub-basin}

Urbanized Mula-Mutha sub-basin consists of mega city Pune and Pimpri-Chinchwad industrial area. It is a rapidly urbanizing sub-basin where built up lands have increased from $0.58 \%$ in 1980 to $3.66 \%$ in 2009 . Both residential and industrial zones have grown rapidly in this sub-basin. The sprawl is more towards the north-west part of the sub-basin. Waterbodies have also increased from $0.90 \%$ in 1980 to 1.33 $\%$ in 2009 to meet the increasing domestic, industrial and irrigation demands of the growing population. Agricultural lands have increased simultaneously from 7.37 in 1980 to $11.01 \%$ in 2009 to meet the increasing food demands. The increase in built up lands, waterbodies and agricultural lands is at the cost of forests and waste lands (Figure 5). Therefore, forests have decreased from $6.09 \%$ in 1980 to $3.65 \%$ in 2009 and waste lands have also decreased from $18.39 \%$ in 1980 to $13.68 \%$ in 2009. Table 3 given below gives in detail the LU/LC changes for urbanized sub-basin.

Hence, from the results it can be concluded that:

1. Population growth is a major driving force for urbanization in a river basin. The population has increased from 4.164 millions in 1981 to 9.426 millions in 2011 in the Pune city. Urbanization is coupled with industralization and infrastructure development in the Upper Bhima river basin.
2. Population increase has increased the water demands in all the three sub-basins of Upper Bhima river basin. In the unurbanized Ghod sub-basin the waterbodies are increasing to meet the water demands of the growing population basically for domestic and irrigation purposes. On the other hand, in the semi-urbanized Bhima sub-basin and in the urbanized Mula-Mutha sub-basin the increase in the waterbodies is to fulfil the water demands of the increasing population for domestic, industrial and agricultural purposes. All this has resulted in the rapid water resources development in the Upper Bhima river basin.

3. With increase in the population, the built up lands and agricultural lands have increased in all the three subbasins of the Upper Bhima river basin. The increase in the built up land is more rapid in the Mula-Mutha sub-basin. Agricultural practices have intensified in the region to increase the food production in order to meet the food demands of the increasing population.

4. Built up lands, agricultural lands and waterbodies have increased on the expense of decreasing forests and wastelands which is leading to environmental degradation.

5. An overall accuracy of $87 \%$ was obtained in preparing the LU/LC maps with pixel based supervised classification approach. Accuracy can be further improved by using advanced classification approaches.

6. Controlled and planned urbanization, implementing best management practices during agriculture and conservation of the forest is highly recommended for sustainable development of the river basins.

\begin{tabular}{lccccc}
\hline Land Use Type & \multicolumn{3}{c}{ Area (\%) } & \multicolumn{2}{c}{ Changes } \\
\cline { 2 - 6 } & $\mathbf{1 9 8 0}$ & $\mathbf{2 0 0 2}$ & $\mathbf{2 0 0 9}$ & $\mathbf{1 9 8 0 -}$ & $\mathbf{1 9 8 0 -}$ \\
& & & & $\mathbf{2 0 0 2}$ & $\mathbf{2 0 0 9}$ \\
\cline { 2 - 6 } & 6.09 & 4.17 & 3.65 & -1.92 & -2.44 \\
Forest Land & 7.37 & 11.48 & 11.01 & 4.12 & 3.64 \\
Agricultural Land & 0.58 & 1.71 & 3.66 & 1.13 & 3.08 \\
Built Up Land & 0.90 & 1.16 & 1.33 & 0.26 & 0.43 \\
Waterbodies & 18.39 & 14.80 & 13.68 & -3.59 & -4.71 \\
Wasteland & & & & &
\end{tabular}

Table 3: LU/LC changes in urbanized Mula-Mutha sub-basin

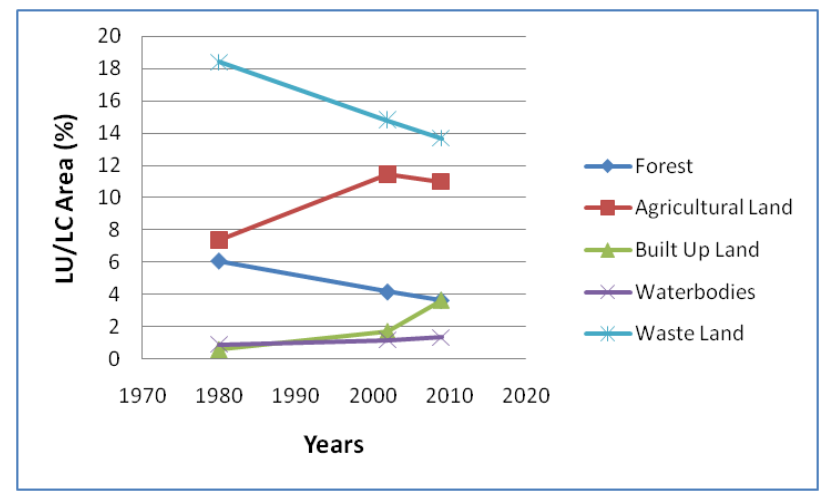

Figure 5: Chart showing LU/LC changes in urbanized MulaMutha sub-basin over a period of 1980, 2002 and 2009 
Therefore, for this study it is found that built-up lands, waterbodies and agricultural lands are increasing in all the three sub-basins of the Upper Bhima river basin at the cost of decreasing forests and wastelands. But the change is more drastic in urbanized Mula-Mutha sub-basin compared to semiurbanized Bhima sub-basin and unurbanized Ghod sub-basin. Hence, remote sensing and GIS are efficient tools in studying the changes in the LU/LC classes of river basin ecosystem. Proper urban planning, use of Best Management Practices (BMPs) and land reclamation practices in the agricultural sector are few methods which can be implemented for sustainable development in a sub-tropical river basin.

\section{ACKNOWLEDGEMENTS}

Authors are thankful to Centre of Studies in Resources Engineering (CSRE), IIT Bombay, Mumbai, India for all its support. This work has been carried out in Terrain Evaluation Laboratory of CSRE, IIT Bombay, Mumbai, India.

\section{REFERENCES}

Adepoju, M.O., Millington, A.C. and Tansey, K.T., 2006. Land use/land cover change detection in metropolitan Lagos (Nigeria): 1984-2002. American Society for Photogrammetry \& Remote Sensing (ASPRS) Annual Conference, Reno, Nevada.

Ali, S.A. and Tesgaya, D., 2010. Landuse and landcover change detection between 1985-2005 in parts of highland of eastern Ethiopia using Remote Sensing and GIS techniques. International journal of Geoinformatics, Vol. 6, No. 2, pp. 3540.

Gartley, M.L., George, B., Davidson, B., Malano, H.M. and Garg, K.K., 2009. Hydro-economic modelling of the Upper Bhima catchment, India. $18^{\text {th }}$ World IMACS / MODSIM Congress, Cairns, Australia. Available at: http://mssanz.org.au/modsim09. Accessed on: August 05, 2014.

Joshi, P.K. and Gairola, S., 2004. Land cover dynamics in Garhwal Himalayas- A case study of Balkhila sub-watershed. Journal of the Indian Society of Remote Sensing, Vol. 32, No. 2, pp. 199-208.

Mohan, M., Pathan, S.K., Narendrareddy, K., Kandya, A. and Pandey, S., 2011. Dynamics of urbanization and its impact on land use/land cover: A case study of Megacity Delhi. Journal of Environmental Protection, Vol. 2, pp. 1274-1283, doi:10.4236/jep.2011.29147.

National Informatics Center (NIC)- District Pune, District Gazetteer Information, 2009. Available online at: http://pune.nic.in/puneCollectorate/Gazette/gaz.aspx, Accessed on: July 12, 2014.

Shukla, S., Khire, M.V. and Gedam, S.S., 2013. Effects of urbanization on river basin ecosystem- A framework. Geoscience and Remote Sensing Symposium (IGARSS), 2013 IEEE International, Melbourne, Australia, pp. 3861-3863, doi: 10.1109/IGARSS.2013.6723674.

Zhou, W., Troy, A. and Grove, M., 2008. Object-based land cover classification and change analysis in the Baltimore metropolitan area using multitemporal high resolution remote sensing data, Sensors, Vol. 8, pp. 1613-1636. 